\title{
CIDADES LÍQUIDAS
}

por Patrícia Cabral de Arruda*

BAUMAN, Zygmunt. Confiança e medo na cidade. Tradução por Miguel Serras Pereira. Lisboa: Relógio D’Água, 2006.

Depois de fazer parte das preocupações de importantes sociólogos clássicos, tais como Weber e Simmel, o tema da cidade volta ao centro das discussões na sociedade contemporânea. O espaço urbano é o cenário por excelência da vida pública, do trabalho, da geração de renda e riqueza, da produção e do consumo, mas também das aglomerações, do desconhecido, do caos, dos medos visíveis e invisíveis. Atualmente, muitos estudiosos têm voltado sua atenção para a análise do fenômeno urbano, entre eles, um dos mais producentes da atualidade: Zygmunt Bauman.

Sociólogo polonês, professor da Universidade de Leeds, na Inglaterra, esse estudioso dedica-se intensamente a pensar a era atual, denominada por ele de "modernidade líquida". Tem produzido obras sobre os mais variados temas de nossa época: o amor, a comunidade, o Holocausto, a globalização, o medo, a cidade. O estilo ensaístico e fluente, permeado por referências a diversos autores, traz um tom quase apocalíptico, mas curiosamente otimista. Provocativo e instigante, foge de qualquer "enquadramento" teórico, principalmente, dos que se referem à "famigerada" pósmodernidade.

\footnotetext{
Doutoranda em Sociologia pela Universidade de Brasília (UnB).
} 
Quase todos os escritos mais recentes de Bauman enfatizam a idéia de "liquidez", o que demonstra como ele percebe a existência na modernidade: fluida, efêmera, amorfa. A obra em questão, embora não estampe no título, retoma a idéia da passagem da "modernidade sólida" para a "modernidade líquida", já desenvolvida em obras como Modernidade Líquida, Tempos Líquidos, Medo Líquido, entre outras. $\mathrm{O}$ autor demonstra como a complexidade da vida urbana transforma os indivíduos em seres aterrorizados por medos reais ou imaginários, em sujeitos sós, amedrontados e inseguros.

O livro Confiança e Medo na Cidade, ainda sem edição brasileira, é composto por dois ensaios e pela transcrição de intervenção em um congresso (Milão, 2004). Em todos os textos - Confiança e Medo na Cidade, Em Busca de Refúgio na Caixa de Pandora e Viver com Estranhos -, o autor discute as relações entre os seres que habitam a cidade. Segundo ele, nos últimos anos, o medo e a obsessão por segurança ganham espaço, sobretudo, na Europa. Paradoxalmente, ao citar Robert Castel, afirma que vivemos em algumas "das sociedades mais seguras que jamais existiram" (p. 9). Ainda mais contraditoriamente, nos sentimos cada vez mais "ameaçados, inseguros e assustados".

Confiança e Medo na Cidade remete a Freud, ao mencionar que o nosso sofrimento, bem como o medo de sofrer, resulta da precariedade e efemeridade do nosso corpo, diante da "supremacia da Natureza", além da nossa incompetência na elaboração de métodos eficazes de regulação das relações sociais. Quanto aos limites físicos, não temos outra saída a não ser contentarmo-nos com o fato de que nunca poderemos dominar por completo a natureza. Porém, no tocante aos sofrimentos de origem social, não aceitamos limites no que diz respeito às nossas próprias ações.

Vivemos em uma sociedade que "se organizou em torno de uma procura infinita de proteção e da insaciável aspiração à segurança" (p. 11). Precisamos sempre de alguém "mau". Por isso, nossos medos 
estão continuamente relacionados a crimes e malfeitores, e, assim, desconfiamos das pessoas e de suas intenções. Bauman lembra como Castel vincula essa situação ao individualismo contemporâneo, pois, ao suprimirmos a importância das comunidades e corporações, obrigamos os homens a cuidarem apenas de si mesmos, o que gera incertezas e, conseqüentemente, medo. Segundo Castel, esse sentimento de insegurança surge devido a dois fenômenos típicos da modernidade: por um lado, a supervalorização do indivíduo, ao libertá-lo do "peso" imposto pelas redes e laços sociais em demasia; por outro, a exacerbação dessa liberdade levou esse mesmo indivíduo a se sentir frágil e vulnerável.

Para Bauman, na "modernidade sólida", o indivíduo temia a "impossibilidade de se adequar à norma geral", mas, "com o advento da modernidade líquida, o fantasma mais aterrador é o representado pelo medo de ficar para trás" (p. 18). Agora, os medos e perigos se proliferam e advêm de todas as partes: da comida industrializada que consumimos, da depressão, do estresse, das doenças cardiovasculares, da vida sedentária, da falta de emprego ou do excesso de trabalho, da exposição ao sol e das relações sexuais sem preservativos. Por isso, temos a impressão de que o caos está instaurado e de que não nos resta alternativa senão instalar câmeras de segurança, blindar os carros e construir muros. Essas sensações são reforçadas pelos anúncios publicitários que lucram com a venda de equipamentos de segurança e do próprio terror. Em uma interessante passagem, Bauman cita Ray Surette, segundo o qual "o mundo tal como aparece na televisão assemelha-se a um rebanho de 'cidadãos-cordeiros' protegidos dos 'delinqüentes-lobos', por 'policiais cães-pastor'”' (p. 53).

O diálogo com Robert Castel surge, novamente, ao remeter às "classes perigosas", que, originalmente, eram compostas pelo excedente de pessoas que estavam temporariamente fora do mercado de trabalho. Agora, porém, essa camada não é mais considerada 
apta a integrar-se à vida social e essas pessoas são declaradas “inassimiláveis". Não são apenas excedentes, mas supérfluas [redundant]. Serem excluídas permanentemente é seu destino irrevogável. Por isso, transformam-se em classes perigosas. Estar sem trabalho significa que o indivíduo deixou de ser imprescindível. Bauman critica o termo "desempregado", que, segundo ele, sugere mais do que diz ou indica que a norma é o emprego e que, portanto, estar desocupado é uma anormalidade.

Na medida em que não são mais necessários, os componentes das classes perigosas tornam-se os "desclassificados" [underclass]: pessoas que não pertencem a qualquer grupo social, situadas à margem. Não se trata de um grupo "inferior", mas de pessoas que estão "fora", "que não servem para nada" (p. 79). Não possuem conta bancária nem cartão de crédito e, por isso, podem passar facilmente de supérfluas a delinqüentes. $O$ tratamento que recebem é o mais conveniente: "tolerância zero", pois é preciso mantê-las longe, por meio da segregação territorial. Assim, surgem muralhas para separar "nós" e "eles", ordem e caos, paz e guerra. Tudo isso para evitar incômodos. Bauman remete-se a Frederik Barth para demonstrar que as fronteiras não separam as diferenças, pelo contrário, quando são traçadas, as diferenças surgem abruptamente.

O cenário dessa segregação e das lutas por ela engendradas é o espaço urbano. É no âmbito citadino que os problemas de origem global se acumulam, "depósitos de lixo" dos problemas criados pela globalização: distúrbios de ordem macro que se manifestam em nível micro, pois terminam por afetar a população local, o bairro. Paradoxalmente, o autor afirma que é nas próprias cidades que se devem procurar as soluções para os problemas globais.

Para Bauman, há uma característica da cidade que sempre estará presente: ela é um espaço cheio de desconhecidos convivendo em extrema proximidade. Esse traço é uma contínua fonte de incertezas e medo, visto que é impossível evitar a presença de 
estranhos - e estrangeiros - nos espaços públicos. A propósito, os estrangeiros são a própria encarnação do imprevisível. O estranho é, portanto, o perigo: “O desconhecido é uma incógnita variável de todas as equações" (p. 34). Os espaços públicos, por sua vez, são lugares por excelência em que os desconhecidos se concentram e onde irrompem as características da vida urbana, onde ela alcança sua expressão máxima e onde percebemos tudo "o que a diferencia de outros tipos de existência coletiva” (p. 67).

Os estranhos, transformados em indivíduos supérfluos, convertem-se em imigrantes econômicos e representam as "assustadoras forças da globalização" (p. 75). Como os personagens de Brecht, os indivíduos trazem consigo todas as mazelas sociais que são cotidianamente "varridas para debaixo do tapete": guerras, fome, privações. Trazem à tona a fragilidade e a precariedade humanas e aumentam o temor de que sejamos os próximos a nos tornarmos supérfluos.

Ao citar o estudo de Teresa Caldeira sobre São Paulo, o autor mostra como a miríade de condomínios fechados se tornou ghettos voluntários, pois representam "oásis de calma e segurança” em meio aos perigos da vida coletiva urbana (p. 36).

Além dos condomínios fechados, Bauman elenca outras inovações da arquitetura e do urbanismo modernos que moldam os espaços à imagem e semelhança do medo, tais como os observados pelo geógrafo Steven Flusty. São os espaços vetados [interdictory spaces], os espaços fugidios, os espaços espinhosos ou os espaços do medo. Em geral, são lugares dedicados a filtrar, a segregar, a excluir os visitantes inconvenientes. São locais aonde não se pode chegar por falta de vias de acesso, ou onde não se pode estar à vontade em virtude da presença de mecanismos de vigilância. Espaços em que ninguém pode passar despercebido e que revelam uma forma de comportamento que é fruto da diversidade cultural encontrada nas metrópoles: a "mixofobia", ou seja, uma "reação previsível e 
generalizada perante a inconcebível, arrepiante e aflitiva variedade de tipos humanos e de costumes que coexistem nas ruas das cidades" (p. 40). Assim, há uma "tendência que impele a procurar ilhas de semelhança e de igualdade no meio do mar da diversidade e da diferença" (p. 40).

Outro autor com quem Bauman dialoga sobre os medos típicos dos habitantes das cidades é Richard Sennett, segundo o qual a uniformidade do meio faz com que as pessoas "desaprendam" como criar formas de conciliação com os estranhos e aumente o medo delas. Daí, o pavor diante do encontro com os estrangeiros e a tendência à segregação que tanto alimenta os comportamentos "mixofóbicos".

Por outro lado, essa realidade urbana é uma experiência que provoca sentimentos diversos, pois "atrai e repele ao mesmo tempo", e talvez seja justamente por isso que a paisagem seja tão aterrorizante e tão irresistível, simultaneamente, uma vez que nunca faltam novidades e surpresas. Prova disso é que, além da "mixofobia", a cidade causa também a "mixofilia", ou seja, a forte atração pela diferença, um desejo de misturar-se com o diverso porque ele é interessante ou fascinante. Segundo Bauman, os dois comportamentos opostos coexistem no íntimo dos indivíduos urbanizados. Sendo a cidade um lugar tão sedutor, locus da aventura - sensação potencializada pela insegurança e pelo medo -, o autor identifica um dilema contido na seguinte questão: "será possível eliminar o medo suprimindo igualmente o tédio?” (p. 65).

A modernidade líquida é marcada pelo triunfo do progresso econômico, do livre câmbio, do livre consumo e da livre concorrência. É o triunfo da civilização moderna. A esse respeito, Bauman cita Diken e Lausten, que afirmam a inversão do "vínculo milenar entre civilização e barbárie". Para eles, "a vida urbana transforma-se numa selva onde impera o terror" (p. 59). As fontes de perigo passaram a existir dentro da cidade. 
Paralelamente, os símbolos do capitalismo, as grandes corporações mudaram-se para áreas afastadas, deixaram de ter interesses centrados na cidade e, agora, o mínimo que desejam é que os seus habitantes "os deixem em paz". Pedem muito pouco e por isso "não se sentem igualmente obrigados a devolver muito" (p. 62).

Bauman cita Nan Ellin, para quem a pluralidade de problemas e sensações suscitados pela vida urbana demonstra a importância de se construírem "cidades que respeitem as comunidades", tarefa difícil, mas essencial à convivência humana (p. 70).

Depois de pintar um cenário aterrorizante e pessimista, Bauman imprime às suas conclusões um tom conciliador e, de certa maneira, otimista, para que o "líquido" não se desfaça no ar. Segundo ele, o que podemos e devemos fazer é contribuir para aumentar a "mixofilia" e reduzir a "mixofobia" (p. 83).

Ao citar Madeleine Bunting, o autor lembra que o "espírito da cidade" é formado pela gama de interações que acontecem no cotidiano: entre motoristas e passageiros, comerciantes e consumidores, empregados e patrões, e também por encontros fugazes, por gestos apressados que modelam e atenuam a brutalidade da existência humana e urbana. Para tanto, é preciso que (re)aprendamos a conviver com as diferenças, promovendo não a tolerância, mas, acima de tudo, o respeito.

As últimas páginas de Confiança e Medo na Cidade trazem uma reflexão muito apropriada para a discussão proposta. Recorda o tempo em que Bauman, ainda estudante, ouviu de um professor de Antropologia a explicação sobre a datação de um fóssil humano e as conclusões sobre a existência da comunidade em que essa criatura viveu, pois se tratava de um ser que apresentava marcas de uma imperfeição física, mas que resistiu cerca de trinta anos. A partir do exemplo, Bauman afirma que a nossa sociedade se distingue 
de qualquer outro rebanho de animais porque é possível a ela a convivência com inválidos, em virtude da compaixão e dos cuidados prestados a eles, característica exclusivamente humana (p. 86-87). A questão, segundo o autor, é levar esse sentimento de compaixão e solidariedade para além dos muros de nossas casas.

Assim, essa obra torna-se leitura indispensável a todos os pensadores da contemporaneidade, sobretudo, aos que se dedicam a refletir sobre o contexto urbano e sobre como a vida condiciona relações singulares. É indicada, em especial, aos estudiosos da violência, dos medos e fobias característicos dos seres que vivem nas cidades modernas. Destina-se, também, a todos os moradores amedrontados ou inquietos com os problemas gerados pela vida cotidiana, confiantes de que a solução está em nossos atos na casa, no bairro, enfim, na cidade que habitamos e que nos habita a cada um de nós. 